\title{
Healthcare Professional's Perception of Patient Safety Measured by the Hospital Survey on Patient Safety Culture: A Systematic Review and Meta-Analysis
}

\author{
Julia Hiromi Hori Okuyama $\mathbb{D}^{1},{ }^{1}$ Tais Freire Galvao ${ }^{(D},{ }^{2}$ and Marcus Tolentino Silva ${ }^{1}{ }^{1}$ \\ ${ }^{1}$ Universidade de Sorocaba, Graduate Program of Pharmaceutical Science, Sorocaba, Brazil \\ ${ }^{2}$ Universidade Estadual de Campinas, Faculty of Pharmaceutical Sciences, Campinas, Brazil \\ Correspondence should be addressed to Marcus Tolentino Silva; marcusts@gmail.com
}

Received 18 January 2018; Revised 27 May 2018; Accepted 12 June 2018; Published 19 July 2018

Academic Editor: Xiang Gao

Copyright (C) 2018 Julia Hiromi Hori Okuyama et al. This is an open access article distributed under the Creative Commons Attribution License, which permits unrestricted use, distribution, and reproduction in any medium, provided the original work is properly cited.

\begin{abstract}
Objective. To assess the culture of patient safety in studies that employed the hospital survey on patient safety culture (HSOPS) in hospitals around the world. Method. We searched MEDLINE, EMBASE, SCOPUS, CINAHL, and SciELO. Two researchers selected studies and extracted the following data: year of publication, country, percentage of physicians and nurses, sample size, and results for the 12 HSOPS dimensions. For each dimension, a random effects meta-analysis with double-arcsine transformation was performed, as well as meta-regressions to investigate heterogeneity, and tests for publication bias. Results. 59 studies with 755,415 practitioners surveyed were included in the review. 29 studies were conducted in the Asian continent and 11 in the United States. On average studies scored 9 out of 10 methodological quality score. Of the 12 HSOPS dimensions, six scored under $50 \%$ of positivity, with "nonpunitive response to errors" the lowest one. In the meta-regression, three dimensions were shown to be influenced by the proportion of physicians and five by the continent where survey was held. Conclusions. The HSOPS is widely used in several countries to assess the culture of patient safety in hospital settings. The culture of culpability is the main weakness across studies. Encouraging event reporting and learning from errors should be priorities in hospitals worldwide.
\end{abstract}

\section{Introduction}

Health institutions, which are known to be complex organizations, have over the years devised improvement strategies and added quality to the health care service [1]. Patient's safety culture reflects the perceptions of processes, norms, and attitudes relating to a culture of preventable errors shared by health professionals in the delivery of care [2]. In health environments, behaviors and attitudes shape the culture of each organization [3]. The sharing of beliefs, values, and attitudes related to the patient's safety culture influences the outcome and organizational aspects [4].

Higher culture of patient safety has been shown to be associated with better patient outcomes [5]. Quality in hospital services means providing the patient with multidisciplinary care at minimal risk [6]. Therefore, implementing improvements in organizational and safety culture enhances quality [7].
Surveys are widely used to assess the culture of safety by identifying the perception of health practitioners [8]. Such inquiries allow for a general assessment of the work climate, the relationship between teams or in a given group, communications, professional relationships, and hierarchical relations. They can identify areas that need prioritization for interventions.

Among the validated tools [8], the Hospital Survey on Patient Safety Culture (HSOPS) and the Safety Attitudes Questionnaire (SAQ), both created in the United States of America (US), are widely cited in research that aims to assess the safety culture of patients in different countries [9]. The HSOPS was designed by the US Agency of Healthcare Research and Quality in 2004 and proposes the assessment of 12 dimensions pertaining to the climate of patient safety in hospital setting. Seven dimensions of the survey are related to the work area, three dimensions explore aspects of the safety 
culture in the hospital, and two are outcome variables [10]. The culture of safety is measured by the staff perspective. For each dimension, percentages above $75 \%$ are considered as strengths and below $50 \%$ are areas that need improvement [10].

Since its inception, HSOPS has been translated and validated in several languages and settings [11-17]. To date, no compilation of surveys that employed HSOPS in hospitals in different countries. This comparison would bring valuable sources of strengths and limitations of culture of patient safety.

The aim of present study is to summarize surveys that assessed the culture of patient safety by HSOPS in hospitals worldwide, by means of a systematic review and meta-analysis.

\section{Methods}

2.1. Protocol and Registration. The protocol for this review was prepared in advance and registered in the International Prospective Register of Systematic Reviews (PROSPERO) under registration number CRD42016047941.

2.2. Eligibility Criteria. Studies meeting the criteria were selected as follows: Portuguese, Spanish, or English language; publication date between 2008 and 2015; cross-sectional, hospital-based design; full or partial use of the HSOPS questionnaire; inclusion of staff with direct or indirect patient contact; and surveying one or more categories of health professionals.

Studies were excluded if they were performed outside of the hospital setting, if they were conducted in a single area or unit of the hospital, or if they were lacking in results for each dimension. Additionally, validation studies, duplicate studies, papers with no full-text available, or studies that used qualitative approaches were excluded.

2.3. Information Sources and Search Strategy. The following databases were searched: MEDLINE (via PubMed), EMBASE, SCOPUS, CINAHL, and SciELO.

The search terms used for PubMed that were adapted for the other databases were "HSOPSC OR (Hospital Survey on Patient Safety Culture)".

2.4. Study Selection. The Covidence software platform (www .covidence.org) was used to organize the references and find duplicates. Two independent reviewers screened the titles and abstracts of the papers, with selected papers progressing to the second phase, which was a full-text review. The articles were evaluated according to pre-specified criteria and, in the event of disagreements in either of the two phases, a third reviewer determined the inclusion.

2.5. Data Collection Process. Two reviewers independently summarized the data using a data extraction sheet. The following information was collected from each paper: year, country, proportion of physicians and nurses, sample size, and results for the 12 HSOPS dimensions (Table 1).
2.6. Risk of Bias. Two reviewers evaluated the studies independently using a validated 10 -item tool, which assessed (i) representativeness of the sample, (ii) appropriateness of the recruitment, (iii) adequacy of the sample size, (iv) description of both the study subjects and the setting, (v) response rate, (vi) objective, standard criteria used for the measurement of the condition, (vii) reliability of the measurement of the condition, (viii) appropriateness of the statistical analysis, (ix) important confounding factors/subgroups/differences that were identified and accounted for, and (x) subpopulations that were identified using objective criteria [18]. Disagreements were resolved by consensus.

2.7. Summary Measures and Statistical Analysis. The outcome measure for this study was the proportion of positive responses in each dimension. STATA statistical software V.14.2 was used for all calculations.

For each HSOPS dimension, meta-analyses were performed by grouping the positive scores using the random effects model described by DerSimonian and Laird and the double-arcsine transformation for variance stabilization as proposed by Freeman-Tukey [19, 20]. The prediction confidence interval was also calculated $[20,21]$.

Heterogeneity was assessed by calculating the inverse variance in a fixed-effects model, which was expressed as a percentage of the $I^{2}$ statistic $[20,22]$. Among the study characteristics, possible causes of heterogeneity were investigated: year of publication, proportion of physicians, proportion of nurses, quality scores, and continent where the study was performed. A meta-regression was performed of the doublearcsine transformed results in the method-of-moments model with a restricted maximum likelihood and a modified coefficient variance as suggested by Knapp and Hartung $[23,24]$. Thus, the $\beta$ coefficient, the probability ( $p$ value), and the residual heterogeneity were calculated. Values of $p<0.05$ were deemed significant.

Publication bias (small study effect) was investigated using three approaches for each dimension. The first consisted of a regression of the log odds of the positive results against their standard errors (Egger's test). The second strategy was a regression of the odds against the reciprocal of the sample size (Peters' test). For both tests, probability values below 0.10 were deemed significant [25]. The third approach included a visual assessment of asymmetry in two funnel plots: one that compared sample size against log odds and the other that compared the log odds against the standard errors $[25,26]$.

\section{Results}

The search retrieved 582 studies, of which 59 were included [5, 27-83] (Figure 1).

Eleven studies were published prior to 2011; and 48, between 2011 and 2015 (Table 2). Twenty-nine were conducted in Asia (of note, eight in Iran), 18 occurred in Europe, and 14 occurred in American continent, of which 11 were in the US. Two studies were located in Eurasia (Turkey) and one was in Africa (Egypt). 


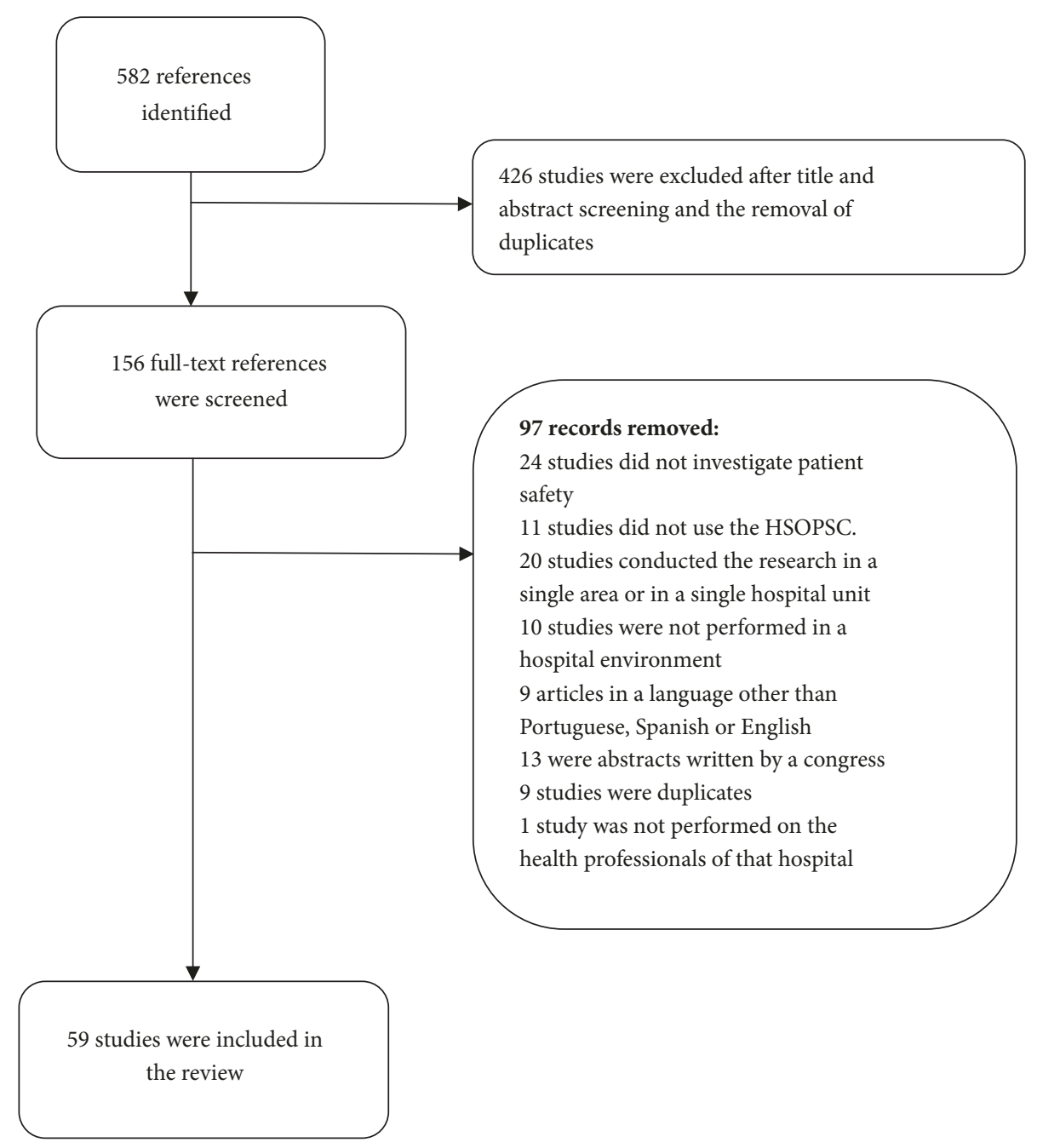

FIGURE 1: Flowchart of included studies.

TABle 1: Hospital Survey on Patient Safety Culture dimensions and what they are intended to measure.

\section{Dimensions of patient safety culture related to the work area or unit}

(1) Teamwork within units

(2) Supervisor/manager expectations and actions that promote patient safety

(3) Organizational learning and continuous improvement

Supervisors and managers consider employee suggestion about patient safety, teamwork and open communication about errors, work hours are adequate to provide the best patient care. Feedback from management, and continuous

(4) Communication openness improvement to avoid errors.

(5) Feedback and communication about error

(6) Staffing

(7) Nonpunitive response to errors

Dimensions explore aspects of the safety culture in hospital

(8) Management support for patient safety

(9) Teamwork across units

(10) Handoffs and Transition

Dimensions of outcome variables

(11) Overall perceptions of patient safety

(12) Frequency of events reported
Hospital management support patient safety and patient care information are not lost during shift change and from one unit to another

Existence of procedures to avoid the occurrence of errors, notifications of possible problems and corrections before they affect the patient 
TABLE 2: Characteristics of included studies $(n=59)$.

\begin{tabular}{|c|c|c|c|c|c|c|}
\hline Continent & Countries & Author, year & Sample size & $\begin{array}{c}\text { Proportion of } \\
\text { physicians }\end{array}$ & $\begin{array}{c}\text { Proportion of } \\
\text { nurses }\end{array}$ & Quality score \\
\hline \multirow[t]{9}{*}{ Africa } & Egypt & Aboul-Fotouh, 2012 & 510 & 50.0 & 32.4 & 10 \\
\hline & Brazil & Silva-Batalha, 2015 & 301 & - & 18.9 & 9 \\
\hline & Colombia & Gómez Ramírez, 2011 & 201 & - & 54.7 & 10 \\
\hline & & Blegen, $2010^{\mathrm{a}}$ & 368 & 40.0 & 33.0 & \multirow{2}{*}{9} \\
\hline & & & 434 & 34.0 & 30.0 & \\
\hline & & Bump, 2015 & 955 & 100.0 & - & 7 \\
\hline & & Campbell, 2010 & 2,163 & 19.9 & 80.1 & 10 \\
\hline & & & 163 & 25.0 & 37.0 & \multirow{3}{*}{10} \\
\hline & \multirow{9}{*}{ United States of America } & Dupree, $2011^{\mathrm{b}}$ & 234 & 21.0 & 48.0 & \\
\hline \multirow{23}{*}{ America } & & & 325 & - & - & \\
\hline & & Halbesleben, 2008 & 148 & - & 100.0 & 10 \\
\hline & & Jones, 2013 & 2,137 & 9.4 & 32.0 & 10 \\
\hline & & Mardon, 2010 & 179 & - & - & 10 \\
\hline & & Patterson, 2015 & 247,140 & 4.7 & 51.2 & 10 \\
\hline & & Ulrich, 2014 & 979 & - & 100.0 & 10 \\
\hline & & Wagner, $2013^{c}$ & 196,462 & 4.0 & 36.0 & 8 \\
\hline & & $\mathrm{Wu}, 2013^{\mathrm{d}}$ & 106,710 & - & 100.0 & 9 \\
\hline & \multirow[t]{3}{*}{ Mexico } & Castañeda-Hidalgo, 2013 & 195 & - & 90.3 & 10 \\
\hline & & Aboshaiqah, 2010 & 445 & - & 100.0 & 10 \\
\hline & & Aboshaiqah, 2013 & 498 & - & 100.0 & 10 \\
\hline & \multirow{5}{*}{ Saudi Arabia } & Alahmadi, 2010 & 1,224 & 8.3 & 60.0 & 9 \\
\hline & & Al-Ahmadi, 2009 & 1,224 & 8.8 & 63.7 & 9 \\
\hline & & Al-Awa, 2012 & 605 & - & 100.0 & 7 \\
\hline & & El-Jardali, 2014 & 2,572 & 8.7 & 50.1 & 10 \\
\hline & & Nie, 2013 & 1,160 & 25.9 & 62.2 & 8 \\
\hline & \multirow[t]{6}{*}{ China } & Shu, 2015 & 2,230 & 31.0 & 69.0 & 10 \\
\hline & & Wang, 2014 & 463 & - & 100.0 & 10 \\
\hline & & Adibi, 2012 & 90 & 7.8 & 71.1 & 3 \\
\hline & & Al-Mandhari, 2014 & 398 & 20.9 & 59.5 & 10 \\
\hline & & Ammouri, 2015 & 414 & - & 100.0 & 10 \\
\hline & & Bahrami, 2013 & 135 & - & 100.0 & 9 \\
\hline & \multirow[t]{7}{*}{ Iran } & & 135 & - & 100.0 & \\
\hline \multirow[t]{17}{*}{ Asia } & & Bahrami, $2014^{\mathrm{f}}$ & 113 & - & 100.0 & 10 \\
\hline & & & 189 & - & 100.0 & 10 \\
\hline & & Davoodi, 2013 & 922 & 10.0 & 77.0 & 10 \\
\hline & & Moussavi, 2013 & 175 & 32.6 & 41.7 & 10 \\
\hline & & Raeissi, 2015 & 461 & 15.2 & 51.0 & 10 \\
\hline & & Fujita, $2013^{\mathrm{h}}$ & 6,963 & 8.5 & 58.1 & 10 \\
\hline & \multirow[t]{2}{*}{ Japan } & Fujita, 2014 & 8,700 & 9.3 & 46.4 & 9 \\
\hline & & $\mathrm{Wu}, 2013^{\mathrm{d}}$ & 4,047 & - & 100.0 & 9 \\
\hline & \multirow{2}{*}{ Jordan } & Khater, 2015 & 658 & - & 100.0 & 10 \\
\hline & & Saleh, 2015 & 242 & - & 100.0 & 10 \\
\hline & Lebanon & El-Jardali, 2010 & 6,807 & 3.7 & 57.8 & 10 \\
\hline & Palestine & Hamdan, 2013 & 1,408 & 20.0 & 49.2 & 10 \\
\hline & \multirow{5}{*}{ Taiwan } & Chen, 2012 & 788 & 29.2 & 60.7 & 10 \\
\hline & & Chen, 2010 & 788 & 29.2 & 60.7 & 10 \\
\hline & & Fujita, $2013^{\text {h }}$ & 10,019 & 9.7 & 57.0 & 10 \\
\hline & & Wagner, $2013^{c}$ & 10,146 & 10.0 & 58.0 & 8 \\
\hline & & $\mathrm{Wu}, 2013^{\mathrm{d}}$ & 5,714 & - & 100.0 & 9 \\
\hline
\end{tabular}


TABLE 2: Continued.

\begin{tabular}{|c|c|c|c|c|c|c|}
\hline Continent & Countries & Author, year & Sample size & $\begin{array}{c}\text { Proportion of } \\
\text { physicians }\end{array}$ & $\begin{array}{c}\text { Proportion of } \\
\text { nurses }\end{array}$ & Quality score \\
\hline \multirow{10}{*}{ Eurasian } & \multirow{2}{*}{ Turkey } & Günes, 2015 & 554 & - & 100.0 & 8 \\
\hline & & Ugurluoglu, 2012 & 108 & 27.8 & 42.6 & 9 \\
\hline & \multirow{4}{*}{ Belgium } & Vlayen, 2012 & 55,225 & 8.8 & 49.8 & 10 \\
\hline & & \multirow{2}{*}{ Hellings, $2010^{g}$} & 3,626 & 12.2 & 60.5 & \multirow{2}{*}{10} \\
\hline & & & 3,940 & 11.7 & 64.1 & \\
\hline & & Vlayen, 2015 & 47,136 & 9.6 & 52.5 & 9 \\
\hline & \multirow{2}{*}{ Croatia } & Brborovic, 2014 & 148 & - & 100.0 & 8 \\
\hline & & Sklebar, 2013 & 560 & - & - & 5 \\
\hline & Scotland & Agnew, 2013 & 1,866 & - & 53.0 & 5 \\
\hline & Western Slovakia & Mikusová, 2012 & 1,787 & 13.6 & 50.5 & 9 \\
\hline \multirow{11}{*}{ Europe } & \multirow{3}{*}{ Spain } & Gama, 2013 & 1,113 & 24.7 & 45.0 & 10 \\
\hline & & Saturno, 2008 & 2,503 & - & - & 8 \\
\hline & & Skodova, 2011 & 299 & - & 40.1 & 10 \\
\hline & \multirow{2}{*}{ Finland } & Kuosmanen, 2013 & 283 & 6.4 & 82.2 & 6 \\
\hline & & Turunen, 2013 & 832 & - & 100.0 & 6 \\
\hline & Italy & Bagnasco, 2011 & 724 & 35.0 & 26.0 & 7 \\
\hline & \multirow{2}{*}{ Norway } & Ballangrud, 2012 & 220 & - & 100.0 & 10 \\
\hline & & Farup, 2015 & 185 & 14.1 & 61.6 & 10 \\
\hline & \multirow{2}{*}{ Netherlands } & Smits, 2012 & 542 & 16.5 & 74.0 & 6 \\
\hline & & Wagner, $2013^{\mathrm{c}}$ & 3,779 & 12.0 & 53.0 & 8 \\
\hline & United Kingdom & Lawton, 2015 & 648 & - & 100.0 & 8 \\
\hline
\end{tabular}

Note. ${ }^{\mathrm{a}, \mathrm{b}, \mathrm{g}}$ Different years: ${ }^{\mathrm{a}} 2006$ and $2007,{ }^{\mathrm{b}} 2005,2008$, and 2011 , and ${ }^{\mathrm{g}} 2005$ and $2007 ;{ }^{\mathrm{c}, \mathrm{d}}$ same study conducted on different continents; ${ }^{\mathrm{e}, \mathrm{f}}$ same study performed in different hospitals; ${ }^{\mathrm{h}}$ same study conducted on different countries.

The studies included 755,415 professionals who answered the HSOPS, of which $55.4 \%$ were nurses and $5.2 \%$ were physicians. Sample sizes ranged from 90 to 247,140 participants (Table 2). The largest studies were conducted in the US [63, 64,78 ] while the smallest studies were Iranian[41].

One study surveyed the same institution three times on different years [37]. Thirty-three studies included a variety of professionals, 22 surveyed nursing staff exclusively and one surveyed only physicians [73]. Four investigations were multi-center studies [31, 35, 51, 66] (surveys administered at different hospitals in the same country) and three were international multi-center surveys $[54,63,64]$.

The mean score for methodological quality of the evaluated articles, on a scale of 0 to 10 , was 9.0 points, with 34 studies that achieved the maximum score (Table 2). Considering the appraisal criteria, 19 studies showed errors in the participant recruitment process, 12 neglected the calculation of sample size, and nine failed to report response rates.

The results of the meta-analyses of the 12 HSOPS dimensions are presented in Table 3 . Five had less than $50 \%$ of positivity in the dimensions of "communication openness", "frequency of events reported", "staffing", "handoffs and transitions", and "nonpunitive response to errors". Only the dimension of "teamwork within units" produced positive responses in $75 \%$ of those surveyed, which was the highest percentage.
A survey that was conducted in Norway in 2012 produced positive responses in $78.8 \%$ of the "nonpunitive response to errors" dimension, [42] and an analysis performed in Spain, reported $3.7 \%$ positivity for the dimension of "management support for patient safety"[39], while seven others had positive scores of less than $30 \%[28,36,40-42,55,72]$.

The meta-analyses detected high heterogeneity values across the HSOPS dimensions, with all that were above $97 \%$. The meta-regression showed that three dimensions were influenced by the proportion of doctors in the dimensions of "overall perceptions of patient safety", "feedback and communication about error", and the "frequency of events reported" (Table 4). The continent where the survey was held significantly affected the dimensions of "supervisor/manager expectations and actions promoting patient safety" (America $72-76 \%$ versus others $42-67 \%$ ), "overall perceptions of patient safety" (America 58-67\% versus others 30-55\%), "communication openness" (America 59-63\% versus others 31-63\%), "staffing" (America 47-64\% versus others 31-63\%), and "nonpunitive response to errors" Asia and Eurasian 23-32\% versus Europa and America 36-58\%). Only the dimensions of "organizational learning-continuous improvement", "teamwork within units", and "handoffs and transitions" were not positive for small study effects. Funnel plot inspections showed asymmetry in all dimensions (data not shown). 
TABLe 3: Meta-analyses of the dimensions and respective heterogeneity $\left(\mathrm{I}^{2}\right)$ of the Hospital Survey on Patient Safety Culture ( $\mathrm{n}=59$ studies).

\begin{tabular}{lcc}
\hline Dimensions & $\begin{array}{c}\text { Positive responses, } \% \\
(95 \% \text { CI })\end{array}$ & $\mathrm{I}^{2}(\%)$ \\
\hline $\begin{array}{l}\text { Teamwork within units } \\
\text { Supervisor/Manager expectations and }\end{array}$ & $75(73-76)$ & 97.9 \\
actions that promote patient safety & $61(59-64)$ & 99.0 \\
Organizational learning and continuous & & 99.3 \\
improvement & $70(67-73)$ & 99.6 \\
Management support for patient safety & $53(48-57)$ & 98.9 \\
Overall perceptions of patient safety & $54(51-56)$ \\
Feedback and communication about error & $54(51-57)$ \\
Communication openness & $47(44-51)$ \\
Frequency of events reported & $48(45-52)$ \\
Teamwork across units & $50(47-53)$ \\
Staffing & $36(33-40)$ \\
Handoffs and transitions & $45(44-47)$ \\
Nonpunitive response to errors & $33(30-37)$ \\
\hline
\end{tabular}

Note. Positive responses in percentage. 95\% CI, 95\% predictive confidence interval.

\section{Discussion}

The present review made it possible to identify studies that used HSOPS and to evaluate the safety culture of patient in hospital setting worldwide. There are still aspects in the safety culture of patient that deserve attention to improve patient care in these environments. HSOPS was used both in a specific class of professionals as well as to all hospital staff.

The dimension "nonpunitive response to errors" was the one with the lowest score and "teamwork among the units" the highest score regarding the patient safety items addressed in the survey. Similar results were found in a systematic review and meta-analysis of the HSOPS conducted to assess the patient's safety culture in hospitals in Iran [84]. This review included Iranian surveys conducted between 2000 and 2014 and used a writing tool as an instrument of critical evaluation, with calculation of meta-analysis using simple means of the domains.

The weakest dimensions were those that were related to communication problems and staffing, with the "nonpunitive response to error" the worst rated dimension. This may reflect the culpability culture of the hospitals but also a comprehensiveness problem. This domain has only negative questions, which induces misunderstanding and less reliability in questionnaires [85]. Dimensions with lower scores may reflect the wording and not the limitation in safety culture. External analyses of HSOPS [86] showed possible weaknesses in its psychometric properties.

Evaluating perceptions of the culture of safety implies the consideration of a number of factors and characteristics pertaining to the hospital setting [87]. Management that is committed to safety culture, effective leadership support, effective communication, sufficient staffing, incentives to capacity-building, and interdisciplinary teamwork are just some of those factors [72]. Unities with different profiles in terms of their constitution and organization (specialized intensive care units, emergency departments, surgical suites, and wards) are found in hospitals [88]. In those unities, perceptions of patient safety vary between practitioners [32, 42]. In this review, the influence of the medical staff was noted for some dimensions. Thus, to assess the perception of patient safety through surveys, the influence of the context of each unit and different professionals should also be considered.

Studies that evaluated the culture of safety have shown contrasting perceptions regarding patient safety in different professionals, and in one study, physicians showed a less positive perception compared to nurses [89] and more positive perceptions compared to the nursing staff in another [90, 91].

The continent where the study was conducted was a source of variability of results across studies. In international multi-center studies [54, 63], a greater proportion of positive scores was found in the US than elsewhere. In addition to the cultural differences [63], the HSOPS was developed in the US; hence its use is more disseminated in that country, a fact that becomes evident in the sample sizes. Another factor detected in those multi-center studies is the larger number of nurses in US hospitals compared to other countries [54], a fact that is attributable to the way hospitals adapt the numbers of nurses to their demand and hire temporary staff.

In a Norwegian study [42], a salient strength was found in the "nonpunitive response to error" dimension. Another study conducted in the same country [92] found a similar value for this dimension. In most studies that were conducted in a variety of countries, this dimension yielded low scores, which indicated the need for improvement. Other investigations were pursued $[28,32,55,58,60,63,70]$ with higher positive percentages in this dimension and seven were found with positive scores above $50 \%$. It was noted that, 


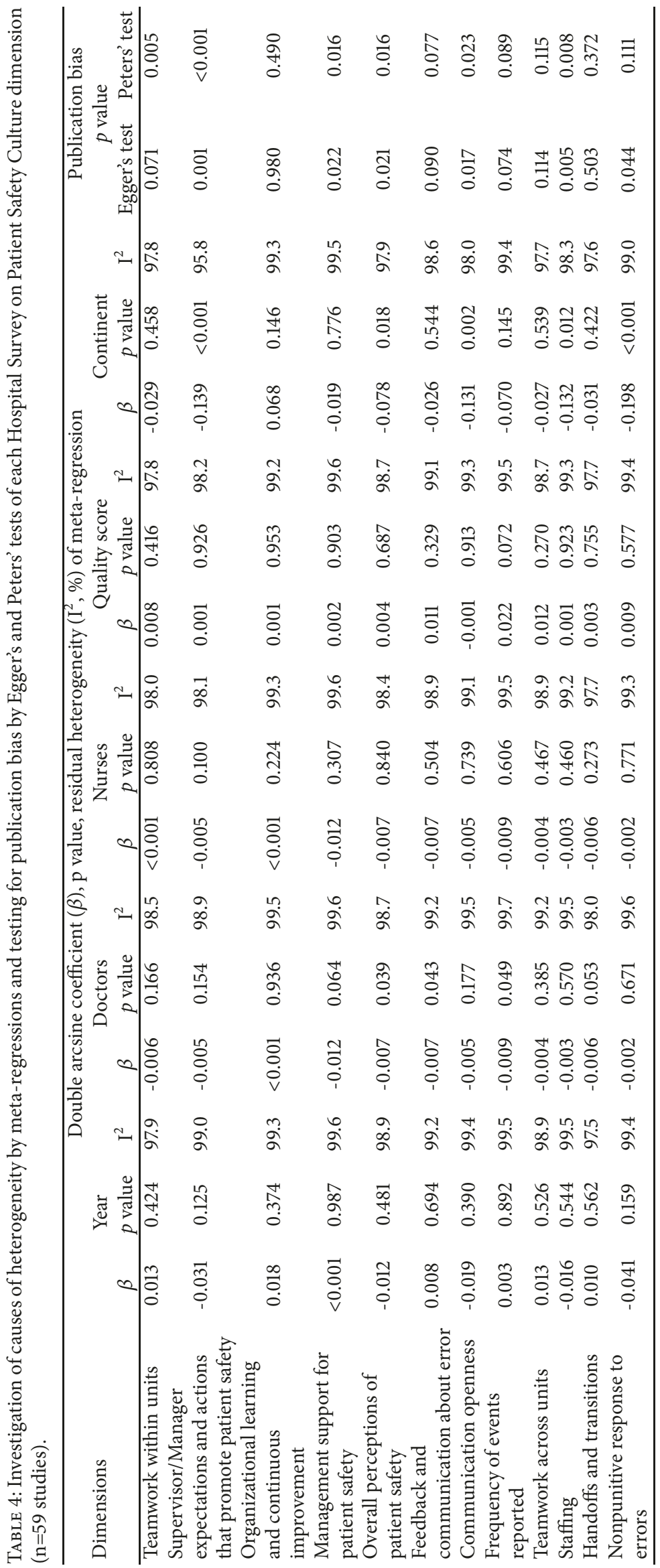


in the settings where these surveys were administered, a climate of encouragement existed in the management staff who promoted reporting and learning from errors.

Included studies showed good methodological quality, which showed no effect on the heterogeneity, partly attributable to the proportion of physicians and the location where the surveys were administered. The statistical tests indicated that small study effect was present and publication bias may have influenced the results. Studies published in scientific conferences and in other gray literature were not included and the restriction of only publications in Portuguese, English, and Spanish may have stressed out this effect. With the purpose of extending the usability and determining the applicability of the HSOPS, all sample sizes and professional categories were included, which influenced the high heterogeneity.

As a psychometric tool, HSOPS adaptation versions [93] are subject to inconsistences due to language and cultural particularities. A previous validation of the tool was not an eligibility criterion in our review. This may have overestimated or underestimated our findings and probably contributed to the high heterogeneity. HSOPS showed good psychometric properties of safety culture [10] when assessed by its development group. Like other questionnaires, the link between the society culture and patient safety may be an issue and could be better explored by qualitative assessment.

The methods of this review were based on internationally recommended standards [94]. Thus, paired reviewers worked on the inclusion, evaluation, and data extraction steps. Data analysis relied on statistical calculations grouped according to relevant variables. The use of the HSOPS is still emerging in some countries. In accordance with the worldwide trend towards patient safety in the health services, this systematic review could foster the use and dissemination of the HSOPS.

\section{Conclusions}

The culture of culpability is pervasive in most of the hospitals that measured the culture of safety using the HSOPS. This behavior reduces error reporting and the likelihood that corrective measures would be implemented. Effective communication, feedback following reporting, engaged leadership, and environments focused on learning from errors are factors that can lead to improvement.

\section{Data Availability}

The data used to support the findings of this study are available upon request from the corresponding author.

\section{Disclosure}

This research received no specific grant from any funding agency in the public, commercial, or not-for-profit sectors.

\section{Conflicts of Interest}

The authors declare that they have no conflicts of interest.

\section{Authors' Contributions}

Julia Hiromi Hori Okuyama selected the studies, extracted the data, assessed the methodological quality of included studies, and drafted the manuscript. Tais Freire Galvao selected studies, extracted the data, and revised the manuscript for important intellectual content. Marcus Tolentino Silva designed the study, analyzed the data, mentored the drafting of the manuscript, and revised it for important intellectual content. All authors agree to be responsible for all aspects of the study and approved the final version of the manuscript.

\section{Acknowledgments}

The authors are grateful to graduate students in pharmacy, Henderson Hirata, for his participation in data extraction and Tathiany Torres, for her participation in critical appraisal of included studies.

\section{References}

[1] M. R. Chassin and J. M. Loeb, "High-reliability health care: Getting there from here," Milbank Quarterly, vol. 91, no. 3, pp. 459-490, 2013.

[2] D. Zohar, Y. Livne, O. Tenne-Gazit, H. Admi, and Y. Donchin, "Healthcare climate: A framework for measuring and improving patient safety," Critical Care Medicine, vol. 35, no. 5, pp. 13121317, 2007.

[3] G. Kaufman and D. McCaughan, "The effect of organisational culture on patient safety," Nursing Standard, vol. 27, no. 43, pp. 50-56, 2013.

[4] S. J. Weaver, L. H. Lubomksi, R. F. Wilson, E. R. Pfoh, K. A. Martinez, and S. M. Dy, "Promoting a culture of safety as a patient safety strategy: A systematic review," Annals of Internal Medicine, vol. 158, no. 5, pp. 369-374, 2013.

[5] R. E. Mardon, K. Khanna, J. Sorra, N. Dyer, and T. Famolaro, "Exploring relationships between hospital patient safety culture and adverse events," Journal of Patient Safety, vol. 6, no. 4, pp. 226-232, 2010.

[6] WHO, World Alliance for Patient Safety: forward programme, Geneva, Switzerland, 2005.

[7] P. M. Dodek, H. Wong, D. K. Heyland et al., "The relationship between organizational culture and family satisfaction in critical care," Critical Care Medicine, vol. 40, no. 5, pp. 1506-1512, 2012.

[8] J. B. Colla, A. C. Bracken, L. M. Kinney, and W. B. Weeks, "Measuring patient safety climate: A review of surveys," Quality \& Safety in Health Care, vol. 14, no. 5, pp. 364-366, 2005.

[9] S. Kristensen and P. Bartels, "Use of Patient Safety Culture Instruments and Recommendations," European Society for Quality in Healthcare. Office for Quality Indicators, 2010.

[10] J. S. N. V. Sorra, Hospital Survey on Patient Safety Culture. (Prepared by Westat, under Contract No. 290-96-0004). AHRQ Publication no 04-0041, Agency for Healthcare Research and Quality, Rockville, MD, USA, 2004.

[11] M. Eiras, A. Escoval, I. M. Grillo, and C. Silva-Fortes, "The hospital survey on patient safety culture in Portuguese hospitals: Instrument validity and reliability," International Journal of Health Care Quality Assurance, vol. 27, no. 2, pp. 111-122, 2014. 
[12] S. Bodur and E. Filiz, "A survey on patient safety culture in primary healthcare services in Turkey," International Journal for Quality in Health Care, vol. 21, no. 5, pp. 348-355, 2009.

[13] H. Brborović, I. Šklebar, O. Brborović, V. Brumen, and J. Mustajbegović, "Development of a Croatian version of the US hospital survey on patient safety culture questionnaire: Dimensionality and psychometric properties," Postgraduate Medical Journal, vol. 90, no. 1061, pp. 125-132, 2014.

[14] S. Ito, K. Seto, M. Kigawa, S. Fujita, T. Hasagawa, and T. Hasegawa, "Development and applicability of Hospital Survey on Patient Safety Culture (HSOPS) in Japan," BMC Health Services Research, vol. 11, article no. 28, 2011.

[15] P. Waterson, P. Griffiths, C. Stride, J. Murphy, and S. Hignett, "Psychometric properties of the Hospital Survey on Patient Safety Culture: Findings from the UK," Quality \& Safety in Health Care, vol. 19, no. 5, 2010.

[16] A. Vlayen, J. Hellings, N. Claes, A. Abdou, and W. Schrooten, "Measuring Safety Culture in Belgian Psychiatric Hospitals: Validation of the Dutch and French Translations of the Hospital Survey on Patient Safety Culture," Journal of Psychiatric Practice, vol. 21, no. 2, pp. 124-139, 2015.

[17] C. T. Reis, J. Laguardia, A. G. Vasconcelos, and M. Martins, "Reliability and validity of the Brazilian version of the Hospital Survey on Patient Safety Culture (HSOPSC): a pilot study," Cadernos de Saúde Pública, vol. 32, no. 11, article e00115614, 2016.

[18] Z. Munn, S. Moola, D. Riitano, and K. Lisy, "The development of a critical appraisal tool for use in systematic reviews addressing questions of prevalence," International Journal of Health Policy and Management, vol. 3, no. 3, pp. 123-128, 2014.

[19] J. J. Barendregt, S. A. Doi, Y. Y. Lee, R. E. Norman, and T. Vos, "Meta-analysis of prevalence," Journal of Epidemiology and Community Health, vol. 67, no. 11, pp. 974-978, 2013.

[20] V. N. Nyaga, M. Arbyn, and M. Aerts, "Metaprop: A Stata command to perform meta-analysis of binomial data," Archives of Public Health, vol. 72, no. 1, article 39, 2014.

[21] R. M. Turner, J. Davey, M. J. Clarke, S. G. Thompson, and J. P. Higgins, "Predicting the extent of heterogeneity in metaanalysis, using empirical data from the Cochrane Database of Systematic Reviews," International Journal of Epidemiology, vol. 41, no. 3, Article ID dys041, pp. 818-827, 2012.

[22] J. P. T. Higgins and S. G. Thompson, "Quantifying heterogeneity in a meta-analysis," Statistics in Medicine, vol. 21, no. 11, pp. 15391558, 2002.

[23] G. Knapp and J. Hartung, "Improved tests for a random effects meta-regression with a single covariate," Statistics in Medicine, vol. 22, no. 17, pp. 2693-2710, 2003.

[24] R. M. Harbord and J. P. T. Higgins, "Meta-regression in Stata," Stata Journal, vol. 8, no. 4, pp. 493-519, 2008.

[25] Z.-C. Jin, X.-H. Zhou, and J. He, "Statistical methods for dealing with publication bias in meta-analysis," Statistics in Medicine, vol. 34, no. 2, pp. 343-360, 2015.

[26] J. P. Hunter, A. Saratzis, A. J. Sutton, R. H. Boucher, R. D. Sayers, and M. J. Bown, "In meta-analyses of proportion studies, funnel plots were found to be an inaccurate method of assessing publication bias," Journal of Clinical Epidemiology, vol. 67, no. 8, pp. 897-903, 2014.

[27] J. R. B. Halbesleben, B. J. Wakefield, D. S. Wakefield, and L. B. Cooper, "Nurse burnout and patient safety outcomes: Nurse safety perception versus reporting behavior," Western Journal of Nursing Research, vol. 30, no. 5, pp. 560-577, 2008.
[28] P. J. Saturno, Z. A. Da Silva Gama, S. L. de Oliveira-Sousa et al., "Analysis of the patient safety culture in hospitals of the Spanish National Health System," Medicina Clínica, vol. 131, no. 3, pp. 18-25, 2008.

[29] T. A. Al-Ahmadi, "Measuring Patient Safety Culture in Riyadh's Hospitals: A Comparison between Public and Private Hospitals," Journal of Egyptian Public Health Association, vol. 84, no. 5-6, pp. 479-500, 2009.

[30] H. A. Alahmadi, "Assessment of patient safety culture in Saudi Arabian hospitals," Quality \& Safety in Health Care, vol. 19, no. 5, 2010.

[31] M. A. Blegen, N. L. Sehgal, B. K. Alldredge, S. Gearhart, A. A. Auerbach, and R. M. Wachter, "Republished paper: Improving safety culture on adult medical units through multidisciplinary teamwork and communication interventions: The TOPS project," Postgraduate Medical Journal, vol. 86, no. 1022, pp. 729-733, 2010.

[32] E. G. Campbell, S. Singer, B. T. Kitch, L. I. Iezzon, and G. S. Meyer, "Patient safety climate in hospitals: Act locally on variation across units," Joint Commission Journal on Quality and Patient Safety, vol. 36, no. 7, pp. 319-326, 2010.

[33] I.-C. Chen and H.-H. Li, "Measuring patient safety culture in Taiwan using the Hospital Survey on Patient Safety Culture (HSOPSC)," BMC Health Services Research, vol. 10, article no. $152,2010$.

[34] F. El-Jardali, M. Jaafar, H. Dimassi, D. Jamal, and R. Hamdan, "The current state of patient safety culture in lebanese hospitals: A study at baseline," International Journal for Quality in Health Care, vol. 22, no. 5, pp. 386-395, 2010.

[35] J. Hellings, W. Schrooten, N. S. Klazinga, and A. Vleugels, "Improving patient safety culture," International Journal of Health Care Quality Assurance, vol. 23, no. 5, pp. 489-506, 2010.

[36] A. Bagnasco, L. Tibaldi, P. Chirone et al., "Patient safety culture: An Italian experience," Journal of Clinical Nursing, vol. 20, no. 7-8, pp. 1188-1195, 2011.

[37] E. Dupree, R. Anderson, M. D. McEvoy, and M. Brodman, "Professionalism: A necessary ingredient in a culture of safety," Joint Commission Journal on Quality and Patient Safety, vol. 37, no. 10, pp. 447-455, 2011.

[38] O. Gómez Ramírez, W. Arenas Gutiérrez, L. González Vega, J. Garzón Salamanca, E. Mateus Galeano, and A. Soto Gámez, "Cultura de seguridad del paciente por personal de enfermería en bogotá, Colombia," Ciencia y enfermería, vol. 17, no. 3, pp. 97-111, 2011.

[39] M. Skodova, M. J. Velasco Rodriguez, and M. A. Fernandez Sierra, "Opinion of healthcare professionals on patient safety in a primary level hospital," Revista de Calidad Asistencial, vol. 26, no. 1, pp. 33-38, 2011.

[40] A. M. Aboul-Fotouh, N. A. Ismail, H. S. Ez Elarab, and G. O. Wassif, "Assessment of patient safety culture among healthcare providers at a teaching hospital in Cairo, Egypt," Eastern Mediterranean Health Journal, vol. 18, no. 4, pp. 372-377, 2012.

[41] H. Adibi, N. Khalesi, H. Ravaghi, M. Jafari, and A. Jeddian, "Development of an effective risk management system in a teaching hospital," Journal of Diabetes \& Metabolic Disorders, vol. 11, no. 1, article 15, 2012.

[42] R. Ballangrud, B. Hedelin, and M. L. Hall-Lord, "Nurses' perceptions of patient safety climate in intensive care units: A crosssectional study," Intensive and Critical Care Nursing, vol. 28, no. 6, pp. 344-354, 2012.

[43] B. Al-Awa, A. Al Mazrooa, O. Rayes et al., "Benchmarking the post-accreditation patient safety culture at King Abdulaziz 
University Hospital," Annals of Saudi Medicine, vol. 32, no. 2, pp. 143-150, 2012.

[44] I.-C. Chen, H.-F. Ng, and H.-H. Li, "A multilevel model of patient safety culture: Cross-level relationship between organizational culture and patient safety behavior in Taiwan's hospitals," International Journal of Health Planning and Management, vol. 27, no. 1, pp. e65-e82, 2012.

[45] V. Mikušová, V. Rusnáková, K. Nad’ová, J. Boroňová, and M. Bet'ková, "Patient safety assessment in Slovak hospitals," International Journal of Collaborative Research on Internal Medicine and Public Health, vol. 4, no. 6, pp. 1236-1244, 2012.

[46] M. Smits, C. Wagner, P. Spreeuwenberg, D. R. M. Timmermans, G. van der Wal, and P. P. Groenewegen, "The role of patient safety culture in the causation of unintended events in hospitals," Journal of Clinical Nursing, vol. 21, no. 23-24, pp. 33923401, 2012.

[47] O. Ugurluoglu, E. Ugurluoglu, P. D. Payziner, and Y. Ozatkan, "Patient safety culture: Sample of a University Hospital in Turkey," Pakistan Journal of Medical Sciences, vol. 28, no. 3, pp. 463-467, 2012.

[48] A. Vlayen, J. Hellings, N. Claes, H. Peleman, and W. Schrooten, "A nationwide hospital survey on patient safety culture in Belgian hospitals: Setting priorities at the launch of a 5-year patient safety plan," BMJ Quality \& Safety, vol. 21, no. 9, pp. 760767, 2012.

[49] A. E. Aboshaiqah and O. G. Baker, "Assessment of nurses' perceptions of patient safety culture in a Saudi Arabia Hospital," Journal of Nursing Care Quality, vol. 28, no. 3, pp. 272-280, 2013.

[50] C. Agnew, R. Flin, and K. Mearns, "Patient safety climate and worker safety behaviours in acute hospitals in Scotland," Journal of Safety Research, vol. 45, pp. 95-101, 2013.

[51] M. A. Bahrami, R. Montazeralfaraj, M. Chalak et al., "Patient safety culture challenges: Survey results of iranian educational hospitals," Middle-East Journal of Scientific Research, vol. 14, no. 5, pp. 641-649, 2013.

[52] H. Castañeda-Hidalgo, R. Garza Hernández, J. F. González Salinas, M. Pineda Zúñiga, G. Acevedo Porras, and A. Aguilera Pérez, "Percepción de la cultura de la seguridad de los pacientes por personal de enfermería," Ciencia y enfermería, vol. 19, no. 2 , pp. 77-88, 2013.

[53] R. Davoodi, M. M. Shabestari, A. Takbiri et al., "Patient safety culture based on medical staff attitudes in Khorasan Razavi Hospitals, northeastern Iran," Iranian Journal of Public Health, vol. 42, no. 11, pp. 1292-1298, 2013.

[54] S. Fujita, K. Seto, S. Ito et al., "The characteristics of patient safety culture in Japan, Taiwan and the United States," BMC Health Services Research, vol. 13, article 20, 2013.

[55] Z. A. Gama, A. C. Oliveira, and P. J. Hernandez, "Patient safety culture and related factors in a network of Spanish public hospitals," Cadernos de Saúde Pública, vol. 29, no. 2, pp. 283293, 2013.

[56] M. Hamdan and A. A. Saleem, "Assessment of patient safety culture in Palestinian public hospitals," International Journal for Quality in Health Care, vol. 25, no. 2, Article ID mzt007, pp. 167175, 2013.

[57] A. Kuosmanen, J. Tiihonen, E. Repo-Tiihonen, M. Eronen, and H. Turunen, "Patient safety culture in two finnish state-run forensic psychiatric hospitals," Journal of Forensic Nursing, vol. 9, no. 4, pp. 207-216, 2013.

[58] K. J. Jones, A. M. Skinner, R. High, and R. Reiter-Palmon, "A theory-driven, longitudinal evaluation of the impact of team training on safety culture in 24 hospitals," BMJ Quality \& Safety, vol. 22, no. 5, pp. 394-404, 2013.

[59] F. Moussavi, J. Moghri, Y. Gholizadeh et al., "Assessment of patient safety culture among personnel in the hospitals associated with Islamic Azad University in Tehran in 2013," Electronic Physician, vol. 5, no. 3, pp. 664-671, 2013.

[60] Y. Nie, X. Mao, H. Cui, S. He, J. Li, and M. Zhang, "Hospital survey on patient safety culture in China," BMC Health Services Research, vol. 13, no. 1, article no. 228, 2013.

[61] I. Šklebar, D. Habek, I. Jurković, L. Šakić, and M. Martinac, "The correlation between patient safety culture and regional anesthesia development," Periodicum biologorum, vol. 115, no. 2, pp. 239-246, 2013.

[62] H. Turunen, P. Partanen, T. Kvist, M. Miettinen, and K. Vehviläinen-Julkunen, "Patient safety culture in acute care: A webbased survey of nurse managers' and registered nurses' views in four Finnish hospitals," International Journal of Nursing Practice, vol. 19, no. 6, pp. 609-617, 2013.

[63] C. Wagner, M. Smits, J. Sorra, and C. C. Huang, "Assessing patient safety culture in hospitals across countries," International Journal for Quality in Health Care, vol. 25, no. 3, pp. 213-221, 2013.

[64] Y. Wu, S. Fujita, K. Seto et al., "The impact of nurse working hours on patient safety culture: A cross-national survey including Japan, the United States and Chinese Taiwan using the Hospital Survey on Patient Safety Culture," BMC Health Services Research, vol. 13, no. 1, article no. 394, 2013.

[65] A. Al-Mandhari, I. Al-Zakwani, M. Al-Kindi, J. Tawilah, A. S. S. Dorvlo, and S. Al-Adawi, "Patient safety culture assessment in Oman," Oman Medical Journal, vol. 29, no. 4, pp. 264-270, 2014.

[66] M. A. Bahrami, M. Chalak, R. Montazeralfaraj, and A. Dehghani Tafti, "Iranian nurses' perception of patient safety culture," Iranian Red Crescent Medical Journal, vol. 16, no. 4, article e11894, 2014.

[67] H. Brborović, O. Brborović, V. Brumen, G. Pavleković, and J. Mustajbegović, "Are nurse presenteeism and patient safety culture associated: a cross-sectional study," Archives of Industrial Hygiene and Toxicology, vol. 65, no. 2, pp. 149-156, 2014.

[68] F. El-Jardali, F. Sheikh, N. A. Garcia, D. Jamal, and A. Abdo, "Patient safety culture in a large teaching hospital in Riyadh: Baseline assessment, comparative analysis and opportunities for improvement," BMC Health Services Research, vol. 14, article no. 122, 2014.

[69] S. Fujita, K. Seto, T. Kitazawa, K. Matsumoto, and T. Hasegawa, "Characteristics of unit-level patient safety culture in hospitals in Japan: A cross-sectional study," BMC Health Services Research, vol. 14, no. 1, article no. 508, 2014.

[70] B. Ulrich and T. Kear, "Patient Safety Culture in Nephrology Nurse Practice Settings: Initial Findings," Nephrology Nursing Journal, vol. 41, no. 5, pp. 459-475, 2014.

[71] X. Wang, K. Liu, L. You et al., "The relationship between patient safety culture and adverse events: A questionnaire survey," International Journal of Nursing Studies, vol. 51, no. 8, pp. 11141122, 2014.

[72] A. A. Ammouri, A. K. Tailakh, J. K. Muliira, R. Geethakrishnan, and S. N. Al Kindi, "Patient safety culture among nurses," International Nursing Review, vol. 62, no. 1, pp. 102-110, 2015.

[73] G. M. Bump, J. Calabria, G. Gosman et al., "Evaluating the Clinical Learning Environment: Resident and Fellow Perceptions of Patient Safety Culture," Journal of Graduate Medical Education, vol. 7, no. 1, pp. 109-112, 2015. 
[74] P. G. Farup, "Are measurements of patient safety culture and adverse events valid and reliable? Results from a cross sectional study," BMC Health Services Research, vol. 15, no. 1, 2015.

[75] Ü. Y. Güneş, Ö. Gürlek, and M. Sönmez, "A survey of the patient safety culture of hospital nurses in Turkey," Collegian, vol. 23, no. 2, pp. 225-232, 2016.

[76] W. A. Khater, L. M. Akhu-Zaheya, S. I. Al-Mahasneh, and R. Khater, "Nurses' perceptions of patient safety culture in Jordanian hospitals," International Nursing Review, vol. 62, no. 1, pp. 82-91, 2015.

[77] R. Lawton, J. K. O’Hara, L. Sheard et al., “Can staff and patient perspectives on hospital safety predict harm-free care? An analysis of staff and patient survey data and routinely collected outcomes," BMJ Quality \& Safety, vol. 24, no. 6, pp. 369-376, 2015.

[78] M. E. Patterson, M. S. Bogart, and K. R. Starr, "Associations between perceived crisis mode work climate and poor information exchange within hospitals," Journal of Hospital Medicine, vol. 10, no. 3, pp. 152-159, 2015.

[79] P. Raeissi, N. Reisi, and A. A. Nasiripour, "Assessment of Patient Safety Culture in Iranian Academic Hospitals: Strengths and Weaknesses," Journal of Patient Safety, 2015.

[80] A. M. Saleh, M. W. Darawad, and M. Al-Hussami, "The perception of hospital safety culture and selected outcomes among nurses: An exploratory study," Nursing \& Health Sciences, vol. 17, no. 3, pp. 339-346, 2015.

[81] Q. Shu, M. Cai, H.-B. Tao et al., "What does a hospital survey on patient safety reveal about patient safety culture of surgical units compared with that of other units?" Medicine (United States), vol. 94, no. 27, p. e1074, 2015.

[82] E. M. S. D. Silva-Batalha and M. M. Melleiro, "Patient safety culture in a teaching hospital: Differences in perception existing in the different scenarios of this institution," Texto e Contexto Enfermagem, vol. 24, no. 2, pp. 432-441, 2015.

[83] A. Vlayen, W. Schrooten, W. Wami et al., "Variability of Patient Safety Culture in Belgian acute hospitals," Journal of Patient Safety, vol. 11, no. 2, pp. 110-121, 2015.

[84] S. Azami-Aghdash, F. Ebadifard Azar, A. Rezapour, A. Azami, V. Rasi, and K. Klvany, "Patient safety culture in hospitals of Iran: A systematic review and meta-analysis," Medical Journal of The Islamic Republic of Iran, vol. 29, no. 1, article 251, 2015.

[85] C. A. Schriesheim, R. J. Eisenbach, and K. D. Hill, "The Effect of Negation and Polar Opposite Item Reversals on Questionnaire Reliability and Validity: An Experimental Investigation," Educational and Psychological Measurement, vol. 51, no. 1, pp. 67-78, 1991.

[86] M. A. Blegen, S. Gearhart, R. O’Brien, N. L. Sehgal, and B. K. Alldredge, "AHRQ's hospital survey on patient safety culture: Psychometric analyses," Journal of Patient Safety, vol. 5, no. 3, pp. 139-144, 2009.

[87] N. Taylor, R. Clay-Williams, E. Hogden, J. Braithwaite, and O. Groene, "High performing hospitals: a qualitative systematic review of associated factors and practical strategies for improvement," BMC Health Services Research, vol. 15, no. 1, 2015.

[88] D. S. Kringos, R. Sunol, C. Wagner et al., "The influence of context on the effectiveness of hospital quality improvement strategies: a review of systematic reviews," BMC Health Services Research, vol. 15, no. 1, 2015.

[89] P. J. Pronovost, B. Weast, C. G. Holzmueller et al., "Evaluation of the culture of safety: Survey of clinicians and managers in an academic medical center," Quality \& Safety in Health Care, vol. 12, no. 6, pp. 405-410, 2003.
[90] M. A. Makary, J. B. Sexton, J. A. Freischlag et al., "Operating room teamwork among physicians and nurses: teamwork in the eye of the beholder," Journal of the American College of Surgeons, vol. 202, no. 5, pp. 746-752, 2006.

[91] E. J. Thomas, J. B. Sexton, and R. L. Helmreich, "Discrepant attitudes about teamwork among critical care nurses and physicians," Critical Care Medicine, vol. 31, no. 3, pp. 956-959, 2003.

[92] E. Olsen, "MEDISIN OG VITENSKAP-Ansattesoppfatningeravsykehusetssikkerhetskultur," Tidsskrift for Den norske legeforening, vol. 127, no. 20, pp. 2656-2660, 2007.

[93] B. Boussat, P. François, G. Gandon et al., "Inconsistencies Between Two Cross-Cultural Adaptations of the Hospital Survey on Patient Safety Culture Into French," Journal of Patient Safety, 2017.

[94] Centre for Reviews and Dissemination. Systematic Reviews, CRD's Guidance for Undertaking Reviews in Health Care: CRD, University of York, 2009. 


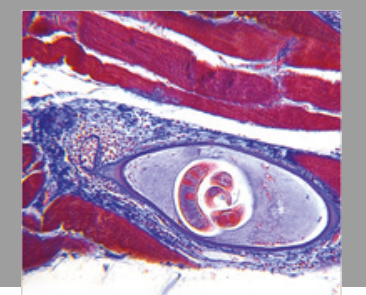

Gastroenterology Research and Practice

$$
=
$$
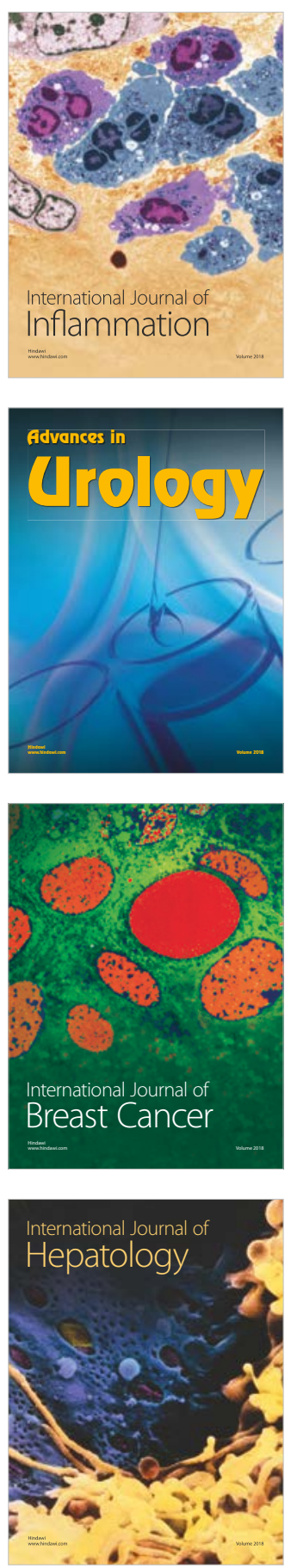

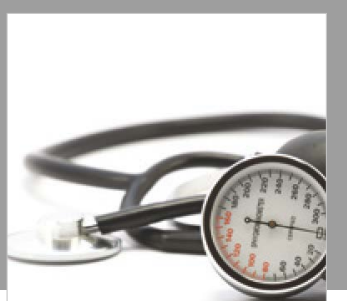

Nursing

Research and Practice

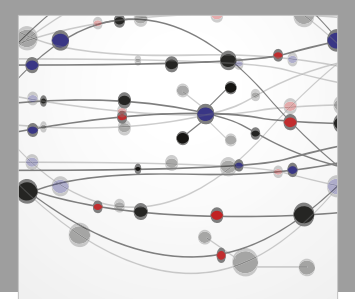

The Scientific World Journal
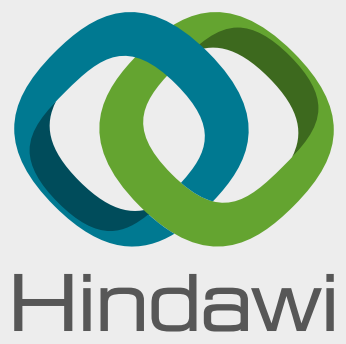

Submit your manuscripts at

www.hindawi.com
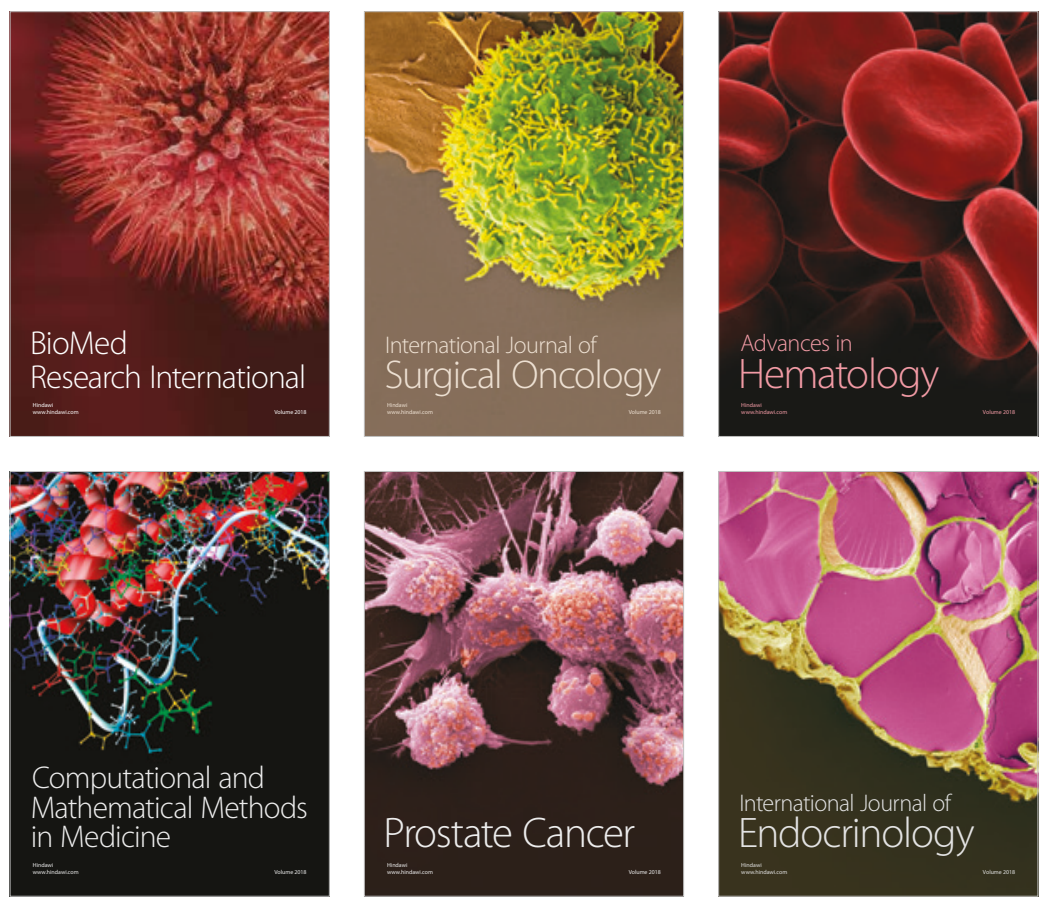

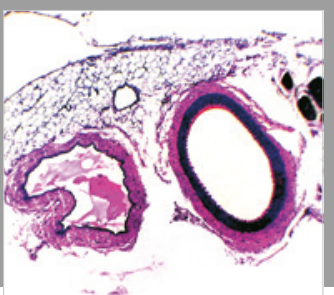

international Journal of Hypertension

Scientifica
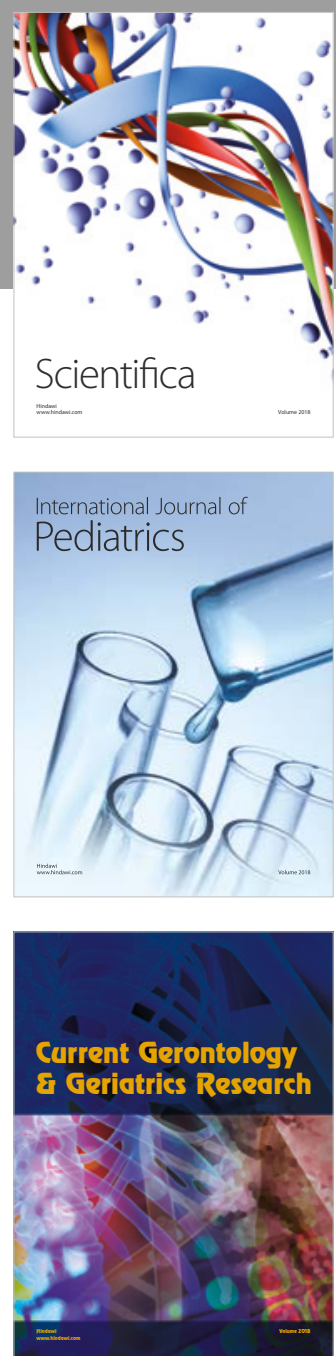

Current Gerontology \& Geriatrics Research
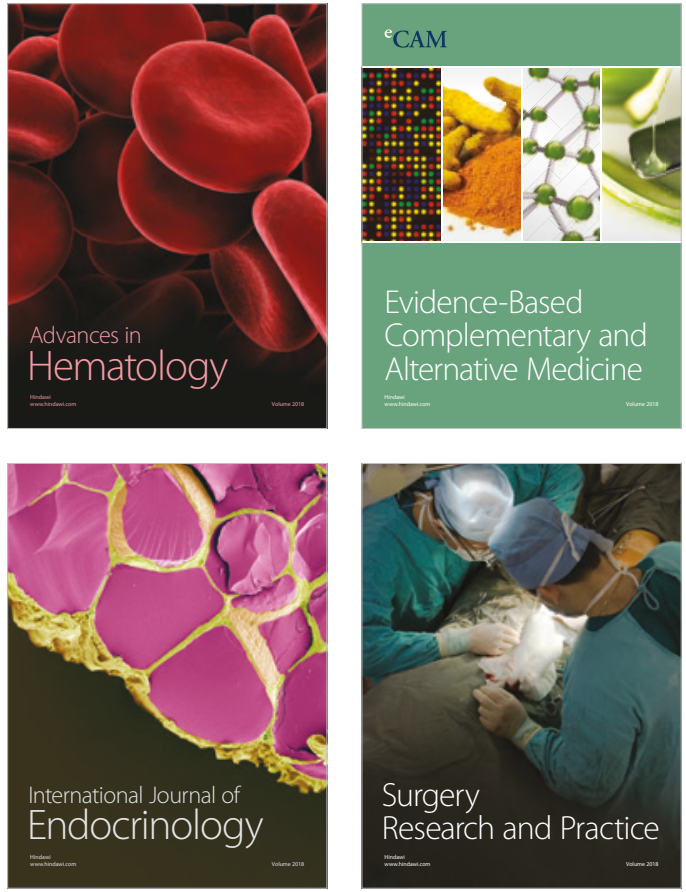